Estudios Públicos 165 (2022), 193-197

DOI: https://doi.org//0.38178/07/83089/|22421053 |

Reseña

James J. Dowd. How Hollywood Imagines War, Schools, Romance, Aging and Social Inequality. London: Routledge, 202 I. US\$34.72 (ISBN: 9780367277I47), I 96 pp.

\title{
Claudia Bossay
}

Universidad de Chile, Chile

\section{- I libro How Hollywood Imagines War, Schools, Romance, Aging and Social Inequality, escrito por el profesor emérito en sociología de la} Universidad de Georgia, James J. Dowd, es un ambicioso proyecto sociológico que abarca cine realizado desde 1937 hasta 2018, con capítulos que exploran docenas o incluso cientos de filmes. El autor introduce su obra planteando que se referirá a "películas y [al] modo en que estas interpretan e imaginan las vidas humanas en el mundo de hoy" (1). Para él, las películas son 'productos sociales' fruto del trabajo colaborativo de personas de distintas áreas y profesiones. Objetos culturales complejos los llama, con negrita y cursiva originalmente en el libro, un gesto que no se vuelve a repetir, salvo para la jerarquía de títulos, y, una línea más abajo del primer énfasis, al describir que "el film es un contenedor de significado cultural complejo" (11; traducción propia).

El autor sugiere que la falta de atención de la sociología al cine no se debe a que no se valore dicho arte ni a una negación de la centralidad de aquel en la cultura del siglo XX y en lo que va de este. Más bien, entiende tal omisión como un descuido (oversight) que es consecuencia de la propia historia de la disciplina, cuyo origen es previo a la consolidación del cine.

A los capítulos que se mencionan en el título (la representación de las guerras, las escuelas, el romance, el envejecimiento y la inequidad social) se suma un capítulo sobre la alienación y un análisis sobre la re- 
presentación de género. La gran diversidad de áreas de interés a tratar en este libro pareciera responder a un desarrollo de larga data del autor, plasmado en varios trabajos académicos publicados en formato de paper, acerca de cada uno de estos grandes temas de investigación, si bien con mayor intensidad en los ámbitos de la sociología militar, la sociología del envejecimiento y la teoría social. Precisamente producto del bagaje académico del autor, cada capítulo tiene interesantes apartados teóricos que discuten el estado de cada cuestión, en especial desde la sociología.

Los criterios de selección de la muestra varían en cada capítulo, y en todos ellos hay una explicación y presentación de los ejemplos que Dowd propone. La metodología con "muestras grandes de todas o la mayoría de las películas que cumplen los criterios de muestreo" (4), invoca al rigor de la sociología para elegir los filmes. Efectivamente, junto con descripciones de las películas mencionadas, cada capítulo dedica un significativo porcentaje a lo teórico-metodológico.

Un capítulo que tiene una presentación muy interesante desde la teoría es aquel sobre la alienación. Comienza con una reflexión de Rahel Jaeggi (2014), quien se pregunta: “¿Es que acaso la alienación ya no existe o simplemente que ya no disponemos del concepto?" (106). Dowd describe el concepto como "notoriamente opaco" (105) y procede a explorar cómo este ha desaparecido de la academia, pero no realmente de la sociedad y, por lo tanto, tampoco de las películas. Analiza su corpus interseccionándolo con género y edad, y luego procede a presentar lecciones de cómo enfrentar y reconocer la alienación, más que realizar un análisis sobre determinadas películas.

El análisis sociológico posibilita hacer interesantes exploraciones respecto de la cultura de Estados Unidos. Por ejemplo, el capítulo sobre la guerra titulado 'Patriotic Gore', revisa 45 películas realizadas desde 1942 a 2014, que abordan distintas guerras. En todas ellas, un soldado estadounidense muere en alguna escena. Dowd concluye que la mayoría de esas películas son románticas, en alusión a la idea romántica de la guerra, o al menos así se presenta la escena en donde muere el soldado, en un sacrificio patriótico, que es la más popular de las tendencias en la muestra. En estas películas, el soldado héroe y la romantización de la bandera apoyan el argumento de considerar la guerra como algo inevitable. Las otras tendencias son las trágicas, analíticas e 'incorporacionistas'. 
El autor sugiere que las películas que critican la guerra o a los militares se realizan menos y se ven menos porque se entienden como sinónimos de crítica a la nación misma. Por ende, desde una actitud acrítica, estas películas sufren de una suerte de censura conservadora (27).

No deja de ser grato leer un análisis de cómo Scorsese, Coppola, Rafelson, Nichols, De Palma y otros directores estadounidenses no hicieron eco de la segunda ola del feminismo y sus películas continúan representando a mujeres sin agencia. La reflexión sobre este silencio, más que una denuncia hacia las actitudes de estos directores, tiene que ver con el impacto social de un movimiento y con la permeabilidad de los campos a reaccionar a demandas sociales. Esta reflexión del capítulo que analiza el género, nos brinda interesantes interrogantes, atingentes para cuestionarnos en nuestros propios tiempos.

Sin embargo, estas variadas metodologías confían en que sus lectores sean cinéfilos y hayan visto una gran cantidad de películas, atravesando diversos géneros y a lo largo de distintos períodos. El autor da varios ejemplos por análisis, de forma que el público lector —idealmente tras haber visto algunas de ellas - pueda completar los argumentos planteados y no se quede con meras ilustraciones. En caso de que uno no haya visto tal o cual película — como me encontré yo en la mayoría de las situaciones - Dowd ofrece descripciones de ellas. Pero quizás sea este el espacio peor logrado del libro, ya que tales descripciones se ofrecen desde el argumento de las cintas (qué pasó en la película o quiénes actuaron allí) y no de cómo se ven; vale decir, no desde las sutilezas de la expresión audiovisual, que es a la larga el vehículo de expresión de las representaciones analizadas en el libro.

Esto podría ser algo trivial o un capricho disciplinar de los estudios de cine, que suelen también contemplar la estética y otras descripciones de las escenas. Pero es un elemento relevante cuando algunos capítulos consideran la cantidad de tickets vendidos como un marcador de éxito e impacto de tal o cual película. Este reconocimiento, así como los premios de la academia (los que se convierten en pieza fundamental para seguir las carreras de actores mayores y analizar sus películas en el capítulo sobre la vejez), hablan también del arte y del oficio de lo audiovisual.

Si en las descripciones de las películas que aparecen en los capítulos hubiese una profundización de los aspectos audiovisuales acompañando lo cuantitativo, los ejemplos ayudarían a que el lector que no las ha 
visto pueda imaginarlas, así como Hollywood lo hace, mediante una descripción con sabor a cine, con luz y movimiento en el tiempo. Sin embargo, el análisis se limita a la dimensión argumental o del discurso de las obras, dejando de lado las estrategias utilizadas para construir dicha narración desde lo visual, lo sonoro e incluso el montaje. Si esto sucediese, las películas funcionarían como una costura de las teorías presentadas en cada capítulo al popular objeto cotidiano cine. Por su parte, el espectador siempre se relaciona con el cine desde la emoción, cualquiera sea la que prime en la película, y por ende se produciría una interesante posibilidad de comunicar lo académico a una gran cantidad de personas no académicas. Esto es, hacer que entre los complejos significados que se contienen en el filme, como presenta el autor en la introducción, entrara también la teoría y metodología sociológicas.

Pero, claro, esto sería pedir otro libro, un 'La vida social en las películas. Cómo Hollywood de imagina la guerra, las escuelas, el romance, el envejecimiento y la inequidad social II'. Una parte dos que sea interdisciplinaria, que estime el cine no únicamente como un discurso (que por cierto lo es), sino que también le dé voz al objeto de investigación, sobre todo porque es un medio cuya relevancia en la sociedad ha sido tan grande como, comparablemente, internet. De alguna manera, entonces, se repite aquí aquel 'descuido' para con el cine.

Ya que estamos en el terreno disciplinar de los estudios de cine, este libro asume ciertas cosas sobre su objeto de estudio que me dejan un sabor amargo. Por ejemplo, en el capítulo sobre la educación, el corpus incluye, además de las estadounidenses, algunas películas británicas, pero sin mayor justificación de por qué se las considera, salvo por observarse en ellas, como en las hollywoodenses, una nostalgia por la pedagogía de los clásicos de las humanidades, la cual se refiere a la idea del trabajo intelectual como un valor en sí mismo (33). Sin embargo, no se incluyen producciones australianas ni irlandesas, ni de otros países de habla inglesa, por lo que es extraña tal inclusión, especialmente porque las industrias cinematográficas, si bien colindan y dialogan virtuosamente como coproductoras, no son comparables, como tampoco lo son los sistemas de educación de los países. Asimismo, incluso en la conclusión, donde hay más espacio para explorar los filmes, pues ahí solo se analizan tres, estos se presentan desprovistos de sus respectivos contextos de producción y, lo que es más importante, de circulación y recepción, lo cual es 
bastante sorprendente porque aquí el autor compara tres películas de Kong realizadas en 1933, 1976 y 2005. Pero, sin tales contextos, el ejercicio de comparación es fútil.

Pese a estos comentarios negativos de cómo la metodología aborda el cine, este libro ofrece un muy correcto análisis del pulso de la producción hollywoodense y, por lo tanto, de Estados Unidos. En la obra de Dowd se cuantifica la ausencia casi total de mujeres en las películas examinadas en cada capítulo, así como la dependencia acrítica de las representaciones estereotipadas de las personas mayores de la clase trabajadora. Aún más, se evidencia cuantitativamente la "naturaleza conservadora de la mayoría de las producciones de Hollywood" (4). Se expone, asimismo, cómo las ausencias y los estereotipos evidencian el racismo, la segregación, la intolerancia.

No obstante, aunque esto pudiese parecer una reiteración, todo emprendimiento que pueda ayudar en pos de la discusión y la transformación de las injusticias mundiales arriba mencionadas, han de ser celebradas, y por lo tanto también lo debe ser esta obra. Por mi parte, espero que la segunda parte del libro contenga la exposición de estudios de cine en cuanto disciplina par, desarrollados en un trabajo en conjunto. Se pierde mucho de un filme solo sabiendo de qué trata, sin un cómo esta filmado o cómo fue recibido; sobre todo desde una perspectiva sociológica. La parte dos de esta obra, entonces, contendría la difícil práctica de la transdisciplina y sacaría al objeto de estudio cine de la categoría semimudo en que queda posicionado How Hollywood Imagines War, Schools, Romance, Aging and Social Inequality.

\section{Bibliografía}

Jaeggi, R. 2014. Alientation. New York: Columbia University Press. EP 